\title{
Validation of Electronic Health Record Detection of Patient Safety Outcomes
}

Christopher J. Humphreys MD, Rahim Kachra MD, EdM, Sarah Fletcher, Nishan Sharma MSc EdD, and Shannon M. Ruzycki MD

\section{About the Authors:}

Christopher J. Humphreys, Rahim Kachra and Shannon M. Ruzycki are with the Division of General Internal Medicine, Department of Medicine, University of Calgary

Rahim Kachra and Nishan Sharma are with the Cumming School of Medicine, University of Calgary

Corresponding Author Shannon Ruzycki: sarro@ualberta.ca

Submitted: October 3, 2018. Accepted: April 1, 2019. Published: August 31, 2019. DOI: 10.22374/cjgim.v14i3.321

\begin{abstract}
Background

Adverse events are common for hospitalized Canadians and lead to worse patient outcomes. We aimed to validate the use of our electronic health record (EHR) to monitor important patient safety outcomes.
\end{abstract}

\section{Methods}

EHR data were abstracted for four high-priority safety outcomes: venous thromboembolism (VTE), hypoglycemia, Clostridium difficile (C. difficile) infection, and prolonged nil per os (NPO) orders. A manual chart review was performed to determine the sensitivity and specificity of the EHR for each patient safety outcome.

\section{Results}

The sensitivity and specificity were: $94.3 \%$ and $99.2 \%$ for C. difficile infections, $34.3 \%$ and $88.0 \%$ for VTE, $96.9 \%$ and $96.3 \%$ hypoglycemia, $61.8 \%$ and $98.5 \%$ for prolonged NPO status.

\section{Conclusion}

The EHR is reasonably sensitive and specific in monitoring rates of hypoglycemia, C. difficile infection, and prolonged NPO in medical inpatients. Importantly, validation of EHR data with manual chart review is necessary before using this data to monitor patient safety outcomes.

\section{RESUME}

\section{Contexte général}

Les événements indésirables sont fréquents chez les Canadiens hospitalisés et entraînent une détérioration de létat de santé des patients. Nous voulions valider l'utilisation de notre dossier de santé électronique (DSE) pour surveiller les résultats importants en matière de sécurité des patients. 


\section{Méthodes}

Les données du DSE ont été résumées pour quatre résultats prioritaires en matière d'innocuité : thromboembolie veineuse (TEV), hypoglycémie, infection à Clostridium difficile (C. difficile) et ordonnance prolongée de néant par os (OBNL). Un examen manuel des dossiers a été effectué pour déterminer la sensibilité et la spécificité du DSE pour chaque résultat lié à la sécurité des patients.

\section{Résultats}

La sensibilité et la spécificité étaient : 94,3\% et 99,2 \% pour les infections à C. difficile, $34,3 \%$ et $88,0 \%$ pour la TEV, $96,9 \%$ et $96,3 \%$ pour l'hypoglycémie, $61,8 \%$ et $98,5 \%$ pour le statut d'ANP prolongé.

\section{Conclusion}

Le DSE est raisonnablement sensible et spécifique dans la surveillance des taux d'hypoglycémie, d'infection à $\mathrm{C}$. difficile et d'OBNL prolongé chez les patients hospitalisés en médecine. Il est important de noter que la validation des données du DSE au moyen d'un examen manuel des dossiers est nécessaire avant d'utiliser ces données pour surveiller les résultats en matière de sécurité des patients.

Adverse events are complications caused by healthcare, as opposed to the underlying disease process, that lead to worse outcomes. ${ }^{1}$ One in every 18 hospitalized Canadians experience an adverse event, leading to 500,000 additional hospital days per year and $\$ 685$ million in costs. ${ }^{2}$ Importantly, patients who suffer an adverse event have higher mortality. ${ }^{2}$

The Canadian Institute for Health Information (CIHI) calls for healthcare organizations to make the monitoring of patient safety a priority ${ }^{2}$, however, patient safety outcomes, which include adverse events, near misses, and nonadherence to best practices ("omissions"), are notoriously difficult to measure (Table 1). ${ }^{3,4}$ The gold standard is a chart review, which is too time-consuming and resource-intensive for quality improvement cycles. ${ }^{3,5}$ Staffreporting systems are common but undercount adverse events. ${ }^{4,6,7}$ Risk-adjusted hospital mortality rates or reviews of administrative discharge codes are easily obtainable but too crude for quality improvement initiatives. ${ }^{6,8}$ The ideal patient safety reporting system generates data in real-time, requires minimal effort from healthcare workers to be sustainable and accurately reflects meaningful events.

The electronic health record (EHR) allows for the collection of timely data on patient safety outcomes but may lack contextual data about appropriate omissions. ${ }^{3}$ We sought to validate EHR detection of patient safety outcomes using chart audit as the reference standard.

\section{Methods}

Ethics approval was received from the University of Calgary Conjoint Health Research Ethics Board. The study was funded
Table 1. Definitions of Patient Safety Outcomes

\begin{tabular}{|c|c|c|}
\hline Term & Definition & Example \\
\hline Adverse event & $\begin{array}{l}\text { Complications caused by } \\
\text { healthcare management } \\
\text { as opposed to the disease } \\
\text { itself that results in worse } \\
\text { outcomes, including } \\
\text { prolonged hospitalization, } \\
\text { disability or death. Not all } \\
\text { adverse events are errors. }\end{array}$ & $\begin{array}{l}\text { C. difficile infection after } \\
\text { antibiotic use. }\end{array}$ \\
\hline Errors & $\begin{array}{l}\text { An action or omission that } \\
\text { has the potential to cause } \\
\text { an undesired outcome. } \\
\text { Most errors do not lead to } \\
\text { adverse events. }\end{array}$ & $\begin{array}{l}\text { Antibiotics are ordered } \\
\text { but is not administered } \\
\text { to patient. }\end{array}$ \\
\hline Near miss & $\begin{array}{l}\text { An error that has the } \\
\text { potential to result in a poor } \\
\text { patient outcome but does } \\
\text { not reach the patient or } \\
\text { result in harm. }\end{array}$ & $\begin{array}{l}\text { Incorrect medication } \\
\text { administered to the } \\
\text { patient without resulting } \\
\text { in harm. }\end{array}$ \\
\hline Omissions & $\begin{array}{l}\text { Failure to use an evidence- } \\
\text { based intervention } \\
\text { intended to reduce adverse } \\
\text { events. }\end{array}$ & $\begin{array}{l}\text { Pharmacologic or } \\
\text { mechanical venous } \\
\text { thromboembolism } \\
\text { prophylaxis not ordered } \\
\text { for high-risk inpatients. }\end{array}$ \\
\hline
\end{tabular}

C. difficile $=$ Clostridium difficile

Robert and Wachter, 2018. ${ }^{9}$ 
by the Canadian Society of Internal Medicine Education and Research Fund.

\section{Patient Safety Outcome Definitions}

Four adverse events were chosen from CIHI based on their prevalence, relevance to internal medicine, and feasibility of measurement. ${ }^{2}$ The study team identified relevant contributing errors (near misses and omissions); the near misses, omissions and adverse events were combined into a composite measure that was called "patient safety outcomes." This was done due to the small numbers of adverse events, the importance of detecting errors even when harm does not occur, and the feasibility of measuring certain events using the EHR. ${ }^{9}$ Errors are actions or omissions that have the potential to cause an undesirable outcome; not all errors lead to adverse events and not all adverse events are caused by errors. ${ }^{9}$ Near misses and omissions can be seen as process measures that may lead to an adverse clinical outcome for a patient. ${ }^{9}$

A clinical data analyst with expertise in our EHR created data definitions based on the patient safety outcomes in consultation with two clinicians (SR and RK). The data definitions were used to identify patient safety outcomes during an inpatient admission. Table 2 outlines the definitions used to extract patient safety outcomes from the EHR.

\section{i. Clostridium Difficile}

No identified relevant omissions. Near miss was defined as a negative Clostridium difficile stool PCR test. In our center, this test can only be sent in patients having diarrhea who have risk factors including previous C. difficile infection or recent antibiotic exposure. While testing was pending, the patient was placed on contact precaution and moved into an isolation room, representing a burden on patients, healthcare staff, and the hospital system itself. However, this did not demonstrate the harm that would need to be disclosed to the patient. An adverse event was a positive test not otherwise captured in the near-miss definition. Any patients with positive testing done prior to or within $48 \mathrm{hrs}$ of admission were excluded.

ii. Hypoglycemia

No identified relevant omissions or near misses. An adverse event was defined as any day with a recorded capillary or serum glucose less than $3 \mathrm{mmol} / \mathrm{L}$ or activation of the EHR Hypoglycemia Order Set.

iii. Prolonged NPO Order

Adverse events related to prolonged nil per os (NPO) include decreased patient satisfaction, delirium, and electrolyte

Table 2. Composite Patient Safety Outcomes and Corresponding Data Definitions

\begin{tabular}{|c|c|c|}
\hline Patient Safety Outcome & Category & EHR Data Signal \\
\hline \multirow[t]{2}{*}{ C. difficile } & NM & Order for a C. difficile PCR test \\
\hline & $\mathrm{AE}$ & Positive C. difficile PCR test \\
\hline \multirow[t]{3}{*}{$\begin{array}{l}\text { Venous } \\
\text { thromboembolism }\end{array}$} & 0 & $\begin{array}{l}\text { Missing order for VTE prophylaxis at } 48 \text { hours. } \\
\text { VTE prophylaxis included VKA order, DOAC order, or SCD order. Patients with an INR }>3.0 \\
\text { or platelet count }<50 \times 10^{9} / \mathrm{L} \text { were excluded. }\end{array}$ \\
\hline & NM & $\begin{array}{l}\text { An omission plus a negative radiographic study for VTE* performed } 48 \text { hours after } \\
\text { admission time. }\end{array}$ \\
\hline & $\mathrm{AE}$ & $\begin{array}{l}\text { An omission plus a positive radiographic study for VTE* performed } 48 \text { hours after } \\
\text { admission time. }\end{array}$ \\
\hline Hypoglycemia & $\mathrm{AE}$ & $\begin{array}{l}\text { Capillary glucose }<3 \mathrm{mmol} / \mathrm{L} \\
\text { Serum glucose }<3 \mathrm{mmol} / \mathrm{L} \\
\text { Activation of "Hypoglycemia Order Set" }\end{array}$ \\
\hline Prolonged NPO order & NM & NPO order for or longer than 48 hours \\
\hline
\end{tabular}


abnormalities ${ }^{10}$. We included patients who did not have diet orders or had NPO entered in the EHR for greater than 48 hours. Forty-eight hours was selected to exclude patients who may have had appropriate, temporary NPO orders while awaiting procedures that were delayed for one day.

iv. Venous Thromboembolism

Omissions were patients without an order for VTE prophylaxis at 48 hours from their admission time. Near misses included patients without an order for VTE prophylaxis at 48 hours into their admission who underwent relevant radiographic testing more than 48 hours after admission which was negative. Patients not on appropriate VTE prophylaxis after 48 hours of admission with positive radiographic results for VTE were considered adverse events. All patients that underwent radiographic testing within 48 hours of admission or had the admission diagnosis of VTE were excluded.

\section{Data Abstraction}

EHR data were abstracted for patients admitted to Internal Medicine teaching services in Calgary, Canada. No patients were excluded. The teaching service teams were led by an Internal Medicine specialist and included a combination of learners ranging from medical students to General Internal Medicine fellows.

Using an estimated prevalence of $20 \%$, we determined that 156 patients were required to achieve a minimum power of $80 \%$ for detecting a change in the percentage value of sensitivity from 0.70 to 0.90 based on a target significance level of $0.05 .{ }^{11}$ This sample size was powered to detect an increase in specificity from 0.80 to $0.90{ }^{11}$ The reviewer received a list of patients randomly selected from each patient safety outcome group and included control patients who did not have a patient safety event. Patient safety outcomes were identified from the paper charts using the same definitions as used to collect the EHR event rates. The paper chart auditor $(\mathrm{CH})$ was masked to the patient safety outcomes extracted from the EHR. The chart audit results were compared to the EHR data by a second member of the research team (SR). Discrepancies were resolved by a third reviewer (RK). The EHR and chart review results were compared; sensitivity and specificity were calculated for each patient safety outcome.

Sensitivity, specificity, percent agreement, and other statistical tests were calculated using Microsoft Excel (2018). The chart data was used as the reference standard. Parametric values were compared using chi-squared testing and non-parametric values were compared using the Kruskal-Wallis test. A p-value less than 0.05 was used to define significance for all tests.

\section{Results}

The study population was $44.6 \%$ female, median age 59 years (range 16-100). The median length of stay was 5.2 days (IQR 8.0
Table 3. Patient Characteristics in the Study Population, Control Patients, and Patients Who Had A Safety Outcome

\begin{tabular}{|l|r|r|r|r|}
\hline Characteristic & $\begin{array}{l}\text { All patients } \\
(n=7,527)\end{array}$ & $\begin{array}{l}\text { Controls } \\
(n=3,733)\end{array}$ & $\begin{array}{l}\text { Patient Safety } \\
\text { Outcome } \\
(n=3,794)\end{array}$ & p-value \\
\hline Male (\%) & $4,168(55.4)$ & $2,029(54.3)$ & $2,139(56.4)$ & 0.08 \\
\hline $\begin{array}{l}\text { Mean age } \\
\text { (years, SD) }\end{array}$ & $59(18.6)$ & $59(18.9)$ & $60(18.3)$ & 0.02 \\
\hline $\begin{array}{l}\text { Median } \\
\text { length of stay } \\
\text { (days, IQR) }\end{array}$ & $5.2(2.8-10.8)$ & $4.7(2.5-8.7)$ & $6.1(3.0-13.8)$ & $<0.01$ \\
\hline
\end{tabular}

$\mathrm{IQR}=$ interquartile range; $\mathrm{SD}=$ standard deviation.

days). The most common admitting diagnoses were congestive heart failure (4.7\% of admissions), diabetic ketoacidosis (2.9\%), and exacerbation of chronic obstructive pulmonary disease (2.8\%). Patients who did not have a patient safety outcome (controls) were significantly younger (59 years compared to 60 years; $\mathrm{p}=0.02)$ and had a significantly shorter length of stay $(4.7$ days compared to 6.1 days, $\mathrm{p}<0.01$ ) than patients who did have a patient safety outcome (Table 3 ).

Electronic Health Record (EHR) data were abstracted for a total of 7,527 patients during the period of January 2016 to May 2017. There were 4,503 patient safety outcomes detected using EHR data. These included 1,492 C. difficile outcomes (1,307 near misses and 185 adverse events), 1,657 patients with a VTE safety outcome (1,609 omissions, 38 near misses and 10 adverse events), 809 hypoglycemia outcomes, and 545 patients who were NPO for more than 48 hours. A full chart review was performed on 169 randomly selected patients by a study team member $(\mathrm{CH})$ who was masked to the EHR data (Figure 1).

The chart review included: 77 control patients, 31 who had a hypoglycemic outcome, 34 with a $C$. difficile outcome, 28 patients with a VTE outcome, and 23 patients with an NPO outcome. The sensitivity and specificity of the EHR data is shown in Table 4. The EHR detection of C. difficile outcomes had a sensitivity of $94.3 \%$ and specificity of $99.2 \%$, VTE events were detected with a sensitivity of $34.3 \%$ and specificity of $88.0 \%$, and hypoglycemia had a sensitivity of $96.9 \%$, the specificity of 96.3\%. EHR detection of prolonged NPO status had a sensitivity of $61.8 \%$, the specificity of $98.5 \%$.

\section{Discussion}

Adverse events occur in 5.6\% of the over 2,300,000 annual hospitalizations in Canada, ${ }^{2}$ and up to $40 \%$ may be preventable. ${ }^{1}$ Evaluation of patient safety interventions is limited by challenges in measuring errors, near misses, and adverse events. ${ }^{9}$ EHRs could 


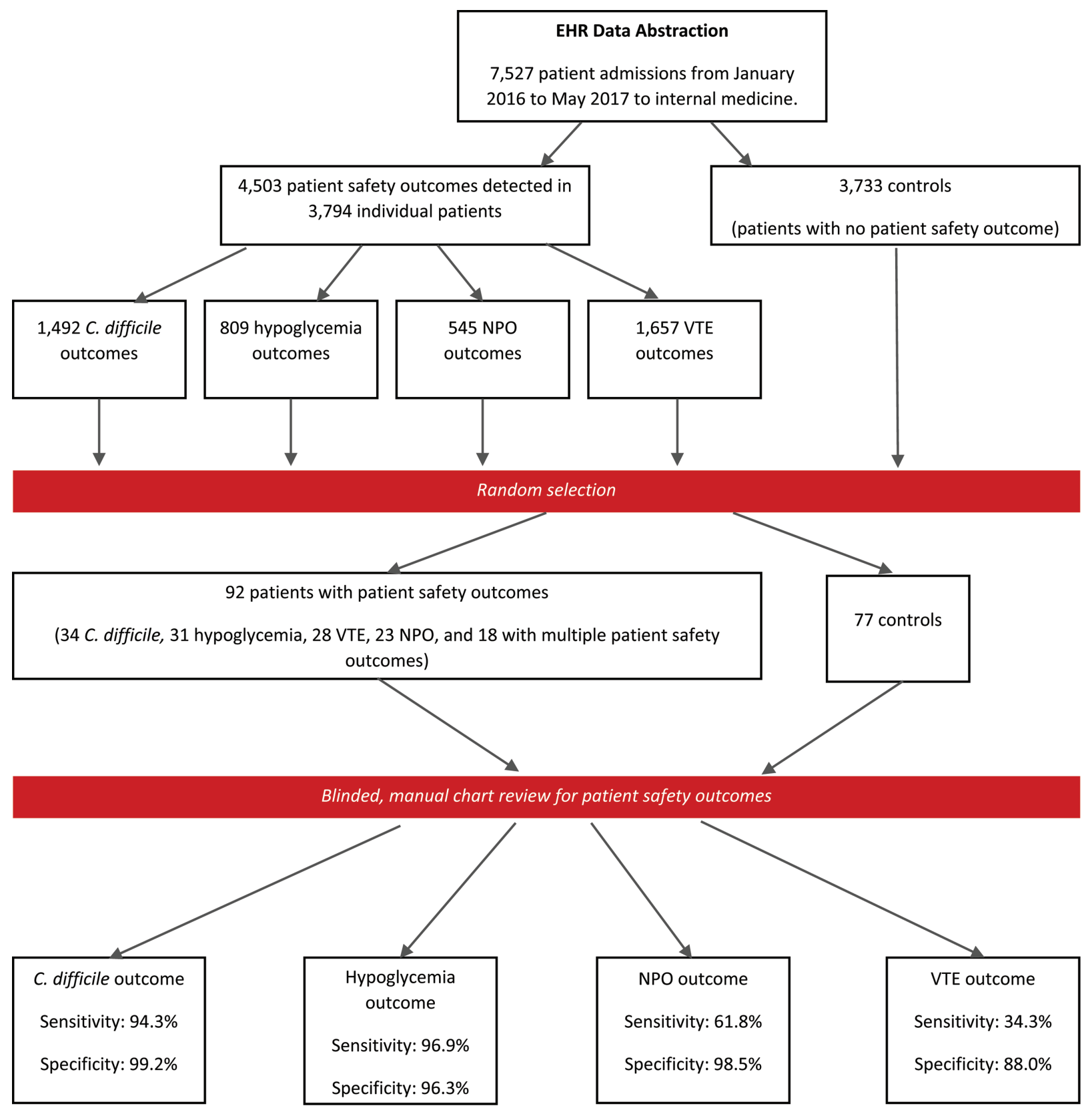

Figure 1. Flow chart demonstrating methodology for validation and results of electronic health record (EHR) determined patient safety outcomes with blinded chart audit.

$\mathrm{EHR}=$ electronic health record; $C$ difficile $=$ Clostridium difficile; $\mathrm{NPO}=$ nil per os; $\mathrm{VTE}=$ venous thromboembolism.

Outcomes defined in Table 2.

be an important tool in patient safety reporting because EHRs may overcome the time delays and resource intensity of other methods. Previous studies have validated EHR for monitoring quality indicators with sensitivities ranging from 34 to $98.5 \%$ and specificity ranging from 88 to $99 \%^{12}$.

Fortunately, individual types of adverse events, such as in-hospital VTE, are rare ${ }^{9}$; however, this limits assessment of the impact of a quality improvement intervention, especially when attempting rapid Plan-Do-Study-Act (PDSA) cycles, because multiple events must be accrued to demonstrate a change. ${ }^{9}$ This can be overcome by combining adverse events with other types of related errors, such as near misses and omissions, that occur more frequently and are part of the critical path leading to an adverse event. ${ }^{9}$

Our validation study demonstrates that rates of patient safety outcomes including hypoglycemia, C. difficile infection, and prolonged NPO status can be measured using the EHR 
Table 4. The Sensitivity and Specificity of Patient Safety Outcomes Detected By Electronic Health Record Data Compared to Chart Audit At Our Institution for Patient Admitted to Teaching Units between January 1, 2016 And May 3, 2017.

\begin{tabular}{|l|l|l|l|}
\hline \multicolumn{1}{|c|}{$\begin{array}{c}\text { Patient Safety } \\
\text { Outcome }\end{array}$} & \multicolumn{1}{c|}{ Sensitivity } & \multicolumn{1}{c|}{ Specificity } & \multicolumn{1}{c|}{ Percent } \\
Agreement*
\end{tabular}

C. difficile $=$ Clostridium difficile, NPO $=$ nil per os .

*Between the two methods (Manual chart review vs. EHR data extraction)

with reasonable sensitivity and specificity. Importantly, our study highlights that EHR data must be validated prior to use because the face validity of EHR measures is not consistently demonstrated by chart audit.

Studies using ICD-9 and ICD-10 codes to detect $C$. difficile infections demonstrate sensitivities of 76 to $81 \%$ and specificities of $99.9 \% .{ }^{8,13}$ Our EHR demonstrated similar sensitivity and specificity, $94.3 \%$ and $99.2 \%$ respectively, for the C. difficile patient safety outcome. The chart audit revelated that the EHR did not capture $C$. difficile testing orders entered during patient transfers; for example, patients without an order for testing had a test result reported, and this occurred after a patient had moved locations. It is not clear why this occurs with our EHR.

Eleven percent of patients in our study suffered a hypoglycemic event. The EHR sensitivity of $96.9 \%$ and specificity of $96.3 \%$ for hypoglycemia is similar to ICD-9 coding, which demonstrates a sensitivity of $88 \%$ and specificity $>99 \%$ compared to chart review. ${ }^{14}$ Our EHR data was not 100\% sensitive for hypoglycemia because some nurses did not enter low glucose measurements into the trackable "Vital Signs" portion of the EHR and were instead documenting the episode in a free-text "Nursing Note". These episodes were treated with juice which does not activate the Hypoglycemia Order Set. This finding highlights the importance of validating EHR data definitions before using the data collected in improvement efforts; the end-users of our EHR were not using the EHR as expected and therefore our data definitions missed these outcomes.

Prolonged NPO periods in medical and surgical inpatients are associated with dehydration, hypoglycemia, and delirium..$^{10,15,16}$ In our study, $7.2 \%$ of inpatients were NPO for greater than 48 hours. Detection of prolonged NPO was $61.8 \%$ sensitive and $98.5 \%$ specific. The chart audit revealed that low sensitivity occurred because healthcare providers often ordered multiple diet orders for patients without deleting previous ones. This resulted in the EHR failing to detect an NPO order for $>48$ hours because of the overlapping older diet orders.

Venous thromboembolism (VTE) is one of the most common preventable adverse events in hospitalized patients. ${ }^{17}$ Our EHR data showed that $21 \%$ of the patients did not receive VTE prophylaxis. However, the sensitivity of our EHR data was poor and significantly lower than other methods. Multiple studies that examine the use of narrative language processing of radiology reports to detect in-hospital VTE have demonstrated sensitivities near $80 \%$ and specificities of $98.5 \% .{ }^{18,19}$ In our study, EHR data did not correctly identify patients with contraindications or ambulatory patients who did not require VTE prophylaxis.

Our study demonstrates that EHR data is adequately sensitive and specific in certain patient safety outcomes to be used in rapid-cycling quality improvement work. The mismatch between EHR data definitions and chart audit for patient safety outcomes with high face validity, such as hypoglycemia, occurred when EHR users deviated from expected processes. More accurate data could be captured with additional parameters being set on data definitions. This should be done in consultation with a local hospital IT expert for the EHR and medical clinicians. There should be an extensive review of definitions prior to utilization for data extraction. This will often require multiple rounds of refinement to find the optimal data definitions which will be health centre specific. Further, all data definitions used should be validated with a select chart review to ensure that the data being collected is what is intended.

An important limitation of our study is that EHR data does not provide a context for whether a patient safety outcome is an error or if it was appropriate care. For example, a patient may be NPO for a prolonged duration due to a bowel obstruction. Though this prolonged period of NPO may still lead to an adverse event such as delirium or an electrolyte abnormality, it was not an error but a side effect of appropriate care. ${ }^{9}$ The trade-off between this level of detail and the feasibility of measurement is a key issue in the collection of patient safety data. ${ }^{9}$ One method that can account for this trade-off between context and resources required for data collection is benchmarking; a quality improvement team accepts that the rate of patient safety outcomes may never be expected to be zero due to acceptable indications. However, they aim to reduce the rate of outcomes to an accepted benchmark or track for unexpected changes in patient safety outcome rates using temporal data collection.

This study was meant to bring awareness to the possibility of using EHR data for quality improvement studies in the clinical setting. As the sophistication of EHRs continue to improve, so will the sensitivity and specificity of the data they can track. 


\section{Conclusion}

Using EHR data to measure adverse event and error rates has advantages over other methods such as chart audit because it requires fewer human resources and can report results more quickly. These characteristics are important in rapid PDSA cycles used in quality improvement. However, these advantages come at the cost of potentially less accurate information. Our study demonstrates that EHR event definitions with face validity, even when developed with clinicians and clinical data specialists, may not capture events as intended. Validation of EHR detection of patient safety outcomes is a necessary step prior to using this data in future quality improvement work.

\section{References}

1. Baker GR, Norton PG, Flintoff V, et al. The Canadian Adverse Events Study: the incidence of adverse events among hospital patients in Canada. CMAJ 2004;170(100):1678-86.

2. Chan B, Cochrane D. Canadian Institute for Health Information, Canadian Patient Safety Institute. Measuring Patient Harm in Canadian Hospitals. With what can be done to improve patient safety? Ottawa, ON: CIHI; 2016.

3. Thomas EJ, Petersen LA. Measuring errors and adverse events in health care. JGIM 2003;18(1):61-67.

4. de Vries EN, Ramrattan MA, Smorenburg SM, Gouma DJ, et al. The incidence and nature of in-hospital adverse events: a systematic review. Qual Saf Health Care. 2008;17(3):216-23

5. Govindan M, Van Citters AD, Nelson EC, et al. Automated detection of harm in healthcare with information technology: a systematic review. Qual Saf Health Care. 2010;19(5):e11.

6. Classen DC, Resar R, Griffin F, et al. 'Global Trigger Tool' shows that adverse events in hospitals may be ten times greater than previously measured. Health Affairs 2011;30(4): https://doi.org/10.1377/hlthaff.2011.0190
7. O'Neil AC, Petersen LA, Cook EF, et al. Physician reporting compared with medical-record review to identify adverse medical events. Ann Intern Med 1993;119(5):370-76.

8. Goto M, Ohl ME, Schweizer ML, et al. Accuracy of administrative code data for the surveillance of healthcare-associated infections: a systematic review and meta-analysis. Clin Infect Dis 2014;58(5):688-96.

9. Robert W, Wachter KG. Understanding patient safety. $3^{\text {rd }}$ edition. New York: McGraw-Hill Education; 2018.

10. Inouye $S$, Charpentier P. Precipitating factors for delirium in hospitalized elderly persons. Predictive model and interrelationship with baseline vulnerability. JAMA 1996;275:852-7.

11. Bujang MA, Adnan TH. Requirements for minimum sample size for sensitivity and specificity analysis. J Clin Diagn Res 2016;10(10):YE01-YE06.

12. Kern LM, Malhotra S, Barron Y, et al. Accuracy of electronically reported "meaningful use" clinical quality measures. Ann Intern Med 2013;158:77-83.

13. Shaklee J, Zerr D, Elward A, et al. Improving surveillance for pediatric Clostridium difficile infection: derivation and validation of an accurate casefinding tool. Pediatr Infect Dis J 2011;30(3):e38-40.

14. Ginde AA, Blanc PG, Lieberman RM, et al. Validation of ICD-9-CM coding algorithm for improved identification of hypoglycemia visits. BMC Endocr Disord 2008;8:4.

15. Gebremedhn EG, Nagaratnam VB. Audit on Preoperative Fasting of Elective Surgical Patients in an African Academic Medical Center. World J Surg 2014;38(9):2200-204.

16. Pompei P, Foreman M, Cassel CK, et al. Detecting delirium among hospitalized older patients. Ann Intern Med 1995;155(3):301-7.

17. Geerts WH, Pineo GF, Heit JA, et al. Prevention of venous thromboembolism. The Eighth ACCP Conference on Antithrombotic and Thrombolytic Therapy. Chest 2008;133:381-433.

18. Rochefort CM, Verma AD, Eguale T, et al. A novel method of adverse event detection can accurately identify venous thromboembolisms (VTEs) from narrative electronic health record data. J Am Med Inform Assoc 2015;22(1):155-65.

19. Tian Z., Sun S., Eguale T., et al. Automated Extraction of VTE Events from Narrative Radiology Reports in Electronic Health Records: A Validation Study. Med Care 2017;55(10):e73-e80.

\title{
Want to share your research?
} Submit to the Canadian Journal of General Internal Medicine

\author{
Reach your colleagues across Canada and abroad, publish in the CJGIM! \\ - Peer-reviewed \\ - Included in the Emerging Citations Index \\ - Published quarterly \\ - Open-access and online-only \\ - CSIM members submit for FREE \\ Original Research • Clinical Reviews • Case Reports • Book Reviews • Scientific Meetings \\ Research Days • Abstracts • And More!
}

Y@CJGIMJournal | www.cjgim.ca 